JPH RECODE Vol. 1 No. 1 (2017)

\title{
EVALUASI SISTEM PENCEGAHAN KEBAKARAN DI PT. CHAROEN POKPHAND INDONESIA PLANT KRIAN, SIDOARJO, JAWA TIMUR
}

\author{
Rr. Vigna Maya Kosha ${ }^{1}$, Indriati Paskarini ${ }^{2}$ \\ ${ }^{1}$ Program Studi S1 Kesehatan Masyarakat, Fakultas Kesehatan Masyarakat, Universitas Airlangga \\ ${ }^{2}$ Departemen Keselamatan dan Kesehatan Kerja, Fak. Kesehatan Masyarakat, Universitas Airlangga \\ Email: vignamayakosha@gmail.com
}

\begin{abstract}
Charoen Pokphand Indonesia, Krian is a company engaged in the animal feed industry and possesses a high level. Purpose of this study was to identify the management in preventing the incidence of fire by implementing a system of preventing management in CPI Krian. This study applied descriptive study using cross-sectional approach. There were as many as twenty informants in this study that consisted of managers, supervisor, SHE, as well as the emergency response team, in which each positions were being represented by five persons. The variables used in this study were the policies management, organization, and procedures; the identification of the risks of fire, development and training, active and passive protections towards the incidence of fire, fire inspection, the prevention of damages.The result showed that the management policy existed and had been socialized down to the workers, the organization and procedure had been well-managed and each division managed its own duties. The identification of the risks of fire was being managed the rate of fire in CPI Lt. Co, in Krian was considered as high. The development and training activities existed and were conducted regularly towards the workers. The means of active and passive protection of fire had been provided and were usable. The fire inspection process had been managed regularly. The attempt of preventing fire had been adjusted and run based on its own chores. Implementation of the fire prevention system is well worth having already contains all the elements that must be executed in managing a fire hazard.
\end{abstract}

Keywords: Attempt of Preventing and Handling Fire Incidence, Management System

\begin{abstract}
ABSTRAK
PT. Charoen Pokphand Indonesia, Krian yaitu merupakan perusahaan yang bergerak dalam bidang industri pakan ternak yang memiliki tingkat risiko kebakaran yang tinggi. Tujuan penelitian ini yaitu untuk mempelajari pelaksanaan sistem pencegahan kebakaran di PT. Charoen Pokphand Indonesia, Krian. Penelitian ini merupakan penelitian deskriptif dengan menggunakan pendekatan cross sectional. Informan dari penelitian ini yaitu antara lain terdiri dari dua puluh lima orang informan yang terdiri dari lima manager, lima supervisior, lima Safety, Health and Environment (SHE) dan sepuluh tim tanggap darurat. Variabel dalam penelitian ini atara lain adalah kebijakan manajemen, organisasi dan prosedur, identifikasi bahaya kebakaran, pembinaan dan pelatihan, sarana proteksi kebakaran aktif dan pasif, inspeksi kebakaran, pengendalian bahaya/ pencegahan, Terdapat Kebijakan manajemen dan sudah disosialisasikan kepada seluruh karyawan. Organisasi dan prosedur sudah terlaksana sesuai dengan tugas masing-masing. Identifikasi bahaya kebakaran menggunakan matriks risiko yang menunjukkan termasuk risiko kebakaran tinggi. Pembinaan dan pelatihan sudah diberikan kepada karyawan secara rutin. Sarana proteksi kebakaran aktif dan pasif sudah ada dan dalam keadaan dapat dipakai. Proses inspeksi kebakaran sudah dilakukan secara rutin. Upaya pengendalian/ pencegahan sudah terbentuk dan sudah dilakukan secara rutin. Penerapan sistem pencegahan kebakaran atau pra kebakaran bernilai sangat baik karena telah memuat semua elemen yang harus dijalankan dalam mengelola bahaya kebakaran.
\end{abstract}

Kata kunci: Sistem Manajemen, Upaya Pencegahan Kebakaran

\section{PENDAHULUAN}

Kebakaran adalah api yang tidak dapat dikendalikan sesuai keinginan dari manusia untuk mengendalikan api tersebut (Ramli, 2010:16). Berdasarkan UU No. 24 tahun 2007 tentang Penanggulangan Bencana, kebakaran merupakan bencana yang berdasarkan penyebab kejadiannya dapat digolongkan sebagai bencana alam (natural disaster) maupun bencana non-alam yang diakibatkan oleh kelalaian manusia (man-made disaster).

Menurut ILO (1992), kebakaran di industri dapat terjadi karena berbagai penyebab, diantaranya gangguan listrik $23 \%$, merokok $18 \%$, permukaan panas $7 \%$, bahan yang terlalu panas $8 \%$, nyala pembakar $7 \%$, percikan api (pekerja las atau pembubut) $5 \%$, pengapian spontan $4 \%$, pengelasan dan pemotongan $4 \%$ dan lain-lain $4 \%$.

Menurut data dan National Fire Protection Association (NFPA), jumlah kasus kebakaran yang terjadi di 50 negara bagian Amerika Serikat tahun 2006 sebanyak 524.000 kasus, tahun 2007 sebanyak 530.500 kasus dan pada tahun 2008 jumlah kebakaran yang terjadi sebanyak 515.000 kasus. (Ramli, 2010).

Menurut US Fire Administration, angka kematian pemadam kebakaran per 100.000 kebakaran di 50 negara bagian Amerika Serikat tahun 2007 berjumlah 119 orang 
JPH RECODE Vol. 1 No. 1 (2017)

(3,53\%), tahun 2008 berjumlah 120 orang $(3,86 \%)$, tahun dimana terjadi ledakan pada mesin produksi itu di area 2009 berjumlah 91 orang (2,97\%), dan tahun 2010 feedmill. Hal ini perlu upaya sistematis dari perusahaan berjumlah 87 orang $(2,78 \%)$. Kematian ini diantaranya untuk mendukung dan menerapkan upaya pencegahan disebabkan karena kelelahan akibat aktivitas fisik yang kebakaran dalam seluruh aspek kehidupan. Mempelajari terlalu berat, kecelakaan kendaraan, tersesat dan terjebak di aspek kebakaran sangat luas dan beragam baik dari segi dalam bangunan yang terbakar, terjatuh dari ketinggian, dan keilmuan, teknis, keahlian atau bisnis.

gangguan kesehatan seperti sesak nafas, serangan jantung dan sebagainya (US Fire Administration, 2010).

Berdasarkan data Dinas Pemadam Kebakaran Provinsi DKI Jakarta, tingkat kejadian kebakaran yang terjadi di Jakarta pada tahun 2005 sebanyak 742 kasus, tahun 206 sebanyak 902 kasus, tahun 2007 sebanyak 855 kasus dan pada tahun 2008 sebanyak 98 kasus kebakaran (Ramli, 2010). Dari data - data di atas, terlihat bahwa bahaya kebakaran merupakan bencana yang serius untuk diperhatikan baik dari sisi korban maupun kerugian yang ditimbulkannya. Secara nasional, kebakaran sangat merugikan karena dapat mengganggu produktivitas nasional dan menurunkan kesejahteraan masyarakat. Oleh karena itu diberbagai negara masalah kebakaran telah dianggap sebagai masalah nasional sehingga penanganannya dilakukan dengan serius.

Kondisi ini melahirkan berbagai lembaga yang bergerak di bidang pencegahan dan penanggulangan kebakaran. Hal ini masih belum dirasakan di Indonesia sehingga kejadian kebakaran dari tahun ketahun terus berulang dan cenderung bertambah tinggi. Sasaran utama dari program manajemen kebakaran adalah untuk mencegah agar kebakaran tidak terjadi melalui upaya pencegahan kebakaran (fire prevention). Pencegahan kebakaran merupakan upaya sistematis untuk menghindarkan teradinya api dengan menerapkan konsep segitiga api. Dalam upaya pencegahan kebakaran ini pendekatan yang dilakukan adalah menghindarkan terjadinya kontak antara ketiga unsur api. Jika kontak tidak terjadi, maka kebakaran juga tidak akan timbul.

Berikut ini adalah beberapa kasus kebakaran yang akhir-akhir ini terjadi di Indonesia, antara lain: Kebakaran pada gedung lantau 6 di PT. Wilmar Nabati Indonesia yang berlokasi di Jalan Kapten Darmo Sugondo 56, Kabupaten Gresik, Jawa Timur, hangus terbakar pada hari Rabu tanggal 8 November 2015 pada pukul 20.0 WIB. Kebakaran yang bermula dari mesin produksi (glycerin) itu seketika menghentikan sementara seluruh aktivitas pabrik pengolahan kelapa sawit tersebut. (www.beritajatim.com). Kebakaran hebat di Jalan Rangkah VII yang menimpa home industri plastik fiber pada hari Sabtu tanggal 17 Oktober 2015 sore, disebabkan dari mesin penggiling plastik yang baru disetting secara digital. (www.lensaindonesia.com)

Tujuan dari penelitian ini adalah mengevaluasi program pra kebakaran yang meliputi kebijakan manajemen tentang penanggulangan kebakaran, organisasi dan prosedur, identifikasi bahaya kebakaran, pembinaan dan pelatihan, sarana proteksi kebakaran, inspeksi kebakaran, dan pengendalian bahaya/pencegahan pada sistem manajemen kebakaran di PT. Charoen Pokphand Indonesia, Krian.

\section{METODE}

Metode penelitian yang digunakan adalah penelitian deskriptif. Jika ditijau dari waktunya, termasuk penelitian cross sectional karena penelitian ini dilakukan sekali saja terhadap objek tertentu pada periode waktu tertentu. Sedangkan berdasarkan proses penelitian yang dilakukan, maka penelitian ini bersifat observasional yang bertujuan untuk mengetahui bagaimana upaya pencegahan kebakaran di PT. Charoen Pokphand Indonesia Pant Krian, Sidoarjo Jawa Timur.

Subjek Penelitian ini adalah staff pekerja keatas dan jajaran manager keatas di PT. Charoen Pokphand Indonesia Plant Krian, Sidoarjo Jawa Timur. Subyek penelitian ini berjumlah 25 orang yang terdiri dari 5 orang manager, 5 orang supervisor, 5 orang $\mathrm{K} 3$ dan 10 orang tim tanggap darurat. Pihak perusahaan memberikan kebijakan bahwa proses wawancara dan observasi dibantu oleh pihak Safety Health and Environment (SHE). Berdasarkan Sugiyono (2011) penelitian ini menggunakan nonprobability sampling dengan teknik purposive sampling yaitu menetapkan sampel dengan cara memilih sampel diantara populasi sesuai yang dikehendaki peneliti, sehingga sampel dapat mewakili karakteristik populasi yang telah dikenal sebelumnya.

Penelitian ini dilaksanakan di PT. Charoen Pokphand Indonesia Plant Krian, Jalan Surabaya Mojokerto KM.26 Sidoarjo Jawa Timur. Waktu penelitian ini dilaksanakan pada bulan Juni hingga Juli 2015. Variabel yang diteliti adalah kebijakan manajemen tentang pencegahan kebakaran, organisasi kebakaran, prosedur kebakaran, identifikasi bahaya kebakaran, pembinaan dan pelatihan, sarana proteksi kebakaran, inspeksi kebakaran, pengendalian bahaya/ pencegahan.

Data yang telah terkumpul selanjutnya diolah secara deskriptif yaitu menggambarkan keadaan secara sistematis

Sebagai perusahaan pakan ternak, PT. Charoen Pokphand Indonesia Krian memiliki banyak mesin produksi yang terus berjalan selama 24 jam tanpa berhenti. Bagian yang paling berpeluang berpotensi timbulnya kebakaran Contohnya seperti mesin grinding, mixing, pelleting, bagian packing, yang beresiko menimbulkan kebakaran.

Kebakaran terjadi di PT. Charoen Pokphand Krian pada HASIL tahun 2013, pada salah satu mesin produksinya yang dan faktual terhadap sasaran yang diteliti, lalu data disajikan dalam bentuk narasi dengan tujuan mempermudah pembacaan hasil penelitian. Hasil analisis tersebut selanjutnya dibandingkan dengan teori yang digunakan untuk menarik kesimpulan sebagai akhir dari penelitian.

Corresponding Author: Rr. Vigna Maya Kosha,

Evaluasi Sistem Pencegahan Kebakaran di PT. Charoen Pokphand Indonesia Plant Krian, Sidoarjo, Jawa Timur 
JPH RECODE Vol. 1 No. 1 (2017)

\section{Kebijakan Manajemen Tentang Pencegahan Kebakaran}

Dari hasil wawancara yang telah dilakukan, sudah ada kebijakan manajemen tentang pencegahan kebakaran yaitu Standard Operational Procedure (SOP) tentang, SOP Alat Pemadam Api Ringan (APAR), SOP Evakuasi Keadaan Darurat, SOP Keselamatan Kerja Kelistrikan, SOP Pemadam Kebakaran, SOP Penyelidikan Insiden dan Pelaporannya, SOP Keselamatan Kerja Di Kantor, SOP Memasuki dan Bekerja Di Ruang Sempit Terkurung, SOP Keselamatan Kerja dan SOP Safety Audit. Di dalam SOP tersebut terdapat langkah-langkah pencegahan dan penanggulangan keadaan darurat, sarana dan prasarana pemadam kebakaran, organisasi penanggulangan tanggap darurat beserta perangkat dan tugasnya. Standard Operational Procedure (SOP) ini sudah diterapkan kepada karyawan dan tenaga kerja di PT. Charoen Pokphand Indonesia, Krian. Standard Operational Procedure (SOP) ini dibuat oleh Tim SHE dan plant manager sebagai penanggung jawab. SOP ini dibuat sejak tanggal 1 November 2004.

Selain itu PT. Charoen Pokphand Indonesia, Krian memiliki kebijakan K3 yang mengacu pada Undangundang No. 1 Tahun 1970 tentang keselamatan kerja, yang berisi : Bahwa setiap tenaga kerja berhak mendapat perlindungan atas keselamatan dalam melakukan pekerjaan untuk kesejahteraan dan meningkatkan produksi serta produktivitas Nasional, bahwa setiap orang lainnya yang berada di tempat kerja perlu terjamin pula keselamatanya, bahwa setiap sumber produksi perlu dipakai dan dipergunakan secara aman dan efisien, bahwa berhubung dengan itu perlu diadakan segala daya upaya untuk membina norma-norma perlindungan kerja, bahwa pembinan norma-norma itu perlu diwujudkan dalam Undang-undang yang memuat ketentuan-ketentuan umum tentang keselamatan kerja yang sesuai dengan perkembangan masyarakat, industri, teknik dan teknologi.

\section{Organisasi Kebakaran}

Di PT. Charoen Pokphand Indonesia, Krian sudahpedoman atau langkah yang harus dilakukan ketika terjadi terdapat organisasi kebakaran yaitu yang disebut juga dengankebakaran.

Emergency Response Team (ERT), organisasi ini sudah Prosedur penanggulangan kebakaran sendiri sangat terlaksana sesuai dengan tugas dan tanggung jawab daripeting sebagai pedoman atau langkah yang harus dilakukan masing-masing bagian. Dari hasil wawancara dijelaskanketika terjadi kebakaran. Berikut ini merupakan prosedur bahwa PT. Charoen Pokphand Indonesia, Krian membentukpenanggulangan kebakaran yang ada di PT. CPI Krian: struktur organisasi kebakaran sejak tanggal 1 Agustus 2005Setiap karyawan dan petugas keamanan (satpam) PT. CPI yang dibuat oleh Tim SHE dan plant manager sebagaiKrian yang mengetahui ada api kebakaran yang masih kecil penanggung jawab.

Berikut tugas dan tanggung jawab Emergency Response Team (ERT) di PT. Charoen Pokphand Indonesia, Krian. Sebagai Ketua RT harus menentukan keadaan darurat atau tidak yang membutuhkan tindakan evakuasi, memberi laporan ke pihak manajemen, memberi perintah pemberhentian tindakan, sebagai ketua operasi saat keadaan darurat dengan memberikan instruksi kepada tim tanggap darurat yang ada, menentukan jenis dan tingkat kedaruratan, memberitahukan dan bekerjasama dengan pihak kepolisian bila perlu, menyelenggarakan pelatihan internal yang berkaitan dengan penanggulangan keadaan darurat, bekerjasama dengan safety dan pihak terkait dalam melakukan investigasi kejadian dan pelaporan, memonitoring dan menginspeksi secara rutin kondisi K3 dan rencana tangga darurat, memfasilitas Jalur pendukung untuk rencana tanggap darurat, yaitu : APAR dan Hydrant, Peta Penempatan P3K, Emergency Drill, Assembly Point (tempat berkumpul).

Sebagai wakil ketua ERT (Emmergency Response Team)harus mengepalai tim tanggap darurat dalam keadan darurat, mengkoordinasikan semua tim tanggap darurat dalam melaksanakan kegiatan saat keadaan darurat, meminta bantuan ke pihak luar jika dibutuhkan tindakan ebih lanjut, membuat peraturan tertulis untuk mencegah erjadinya keadaan darurat, menyusun jadwal pelatihan memipin kegiatan pasca kejadian seperti investigasi dan rehabilitasi, memberi laporan ke ketua ERT, membuat pengajuan pembelian peralatan pendukung rencana tanggap darurat.

Sebagai bagian Keamanan (SATPAM) harus mencegah masyarakat atau orang yang tidak berkepentingan memasuki area kejadian, mengamankan TKP, mengatur lalu lintas dan keamanan pabrik, membantu proses evakuasi. Sebagai karyawan (penghuni gedung) wajib mengikuti latihan pemadaman kebakaran dan evakuasi serta mengetahui letak dan lokasi alat pemadam kebakaran dan rute evakuasi.

\section{Prosedur Kebakaran}

Menurut hasil wawancara kepada manager beserta ahli K3, perusahaan sudah memiliki prosedur evakuasi keadaan darurat dan sudah terlaksana sebagai prosedur yang harus dilaksanakan pada saat keadaan darurat. Prosedur kebakaran ini dibuat oleh Tim SHE dan sejak tanggal 1 Agustus 2005 prosedur ini sudah disahkan oleh plant manager selaku penanggung jawab. Prosedur penanggulangan kebakaran sendiri sangat peting sebagai di pabrik, kantor dan warehouse milik PT. CPI Krian harus berteriak memberitahu orang lain: "API" atau "KEBAKARAN" lalu harus cepat memadamkannya dengan Alat Pemadam Api Ringan jenis Dry Chemical Powder dengan cara menarik pin pengaman katup, mengarahkan slangnya ke dasar api tetapi jangan menentang arah angin, menekan katup untuk mengeluarkan tepung kimia pemadam kebakaran dan membuat gerakan menyapu dari kiri ke kanan, maju dan mundur ke dasar api sampai api padam. 
JPH RECODE Vol. 1 No. 1 (2017)

Jika api tidak bisa dipadamkan, segera tekan tombol alarm kebakaran yang terdekat sampai bel alarm kebakaran berbunyi. Tinggalkan pabrik, kantor dan warehouse melalui jalur evakuasi yang aman menuju ke arah luar tempat berkumpul (Assembly Point) untuk dilakukan "Head Count". Jangan sekali-kali anda menyelamatkan barangbarang pribadi milik anda seperti uang, perhiasan, pakaian dan lain-lain. Utamakan keselamatan diri anda dan orang lain di atas segalanya, saat terjadi kebakaran waktu dan kesempatan menyelamatkan diri sangat singkat.

Assembly point atau tempat yang dianggap aman untuk berkumpul pada masing-masing pabrik berbeda-beda letaknya. Pakaian Tahan Api adalah peralatan pelindung yang harus dipakai oleh regu pemadam kebakaran PT. CPI Krian sebelum memadamkan api. Pakaian tahan api terdiri atas Hard Hat dengan Face Shields atau Safety Glass, Fire Fighters Gloves, Coat and Pants, Fire Boots. Para Manager dan supervisor shift / pengawas yang bertugas pada saat itu di tempat kejadian akan bertindak berturut-turut sebagai "Fire Marshall" dan "Assistant Fire Marshall". Karyawan atau petugas satpam yang menekan tombol alarm kebakaran harus cepat memberitahu Fire Marshall dimana lokasi kebakaran berada, apakah ada korban manusia, apa yang terbakar dan seberapa besarna api kebakaran agar Fire Marshall dan Assistant Fire Marshall dapat bertindak lebih cepat.

\section{Identifikasi Bahaya Kebakaran}

Identifikasi risiko bahaya kebakaran yang telah dilakukan oleh PT. Charoen Pokphand Indonesia Krian berupa identifikasi bahaya, penilaian, dan pengendalian risiko di PT. Charoen Pokphand Indonesia Krian. Identifikasi bahaya kebakaran dilakukan oleh tim SHE sejak 1 September 2006 dan plant manager sebagai penanggung jawab. Identifikasi bahaya, penilaian, dan pengendalian risiko yang dilakukan di PT. CPI Krian berupa pemaparan dari kegiatan, identifikasi bahaya, penilaian risiko yang terdiri dari penilaian akibat, peluang dan hasil dari tingkat risiko beserta pengendalian risiko. Identifikasi kegiatan berupa, welding, mengisi tangki (oli, solar, air), pembersihan mesin crumble dan pellet, pengukuran dan pencatatan parameter mesin, proses mesin extruder, pekerja di bagian packing, menjadi operator tungku drier batubara, menaiki sak BB untuk memudahkan pembongkaran pada bongkar $\mathrm{BB}$, membersihkan magnit pada mesin hammermill, dan panel MCC mixer berada dalam ruangan yang sama dengan operator mixer room.

Menurut hasil observasi lapangan, sumber panas yang terdapat dalam PT. Charoen Pokphand Indonesia, Krian berasal dari panas yang ditimbulkan dari

Gambar 1. Alat Pemadam Api Ringan di PT. CPI Krian. pengoperasian mesin extruder dan mesin pellet. Penilaian risiko kebakaran menggunakan matrik risiko kebakaran menunjukkan bahwa risiko kebakaran di PT. Charoen Pokphand Indonesia, Krian adalah tinggi karena kemungkinan untuk terjadi kebakaran adalah pernah terjadi dengan tingkat keparahan berat.

\section{Pembinaan dan Pelatihan}

Program pembinaan dan pelatihan di PT. Charoen Pokphand Indonesia, Krian sudah ada dan program pelatihan sudah terlaksana secara rutin dan terjadwal selama 6 bulan sekali. Pembinaan dan pelatihan dilakukan oleh Tim SHE didampingi plant manager selaku penanggung jawab. Menurut hasil wawancara dengan SHE, program dan pelatihan yang sudah dilakukan berupa in house training setiap 6 bulan sekali. kegiatan yang sudah dilakukan dalam in house training tersebut yaitu pendidikan kilat yang meliputi pembacaan kebijakan K3, peraturan perundangan dan Standard Operational Procedure (SOP) tentang tanggap darurat dan tentang P2K3 (Panitia Pembina Keselamatan dan Kesehatan Kerja). Selain itu terdapat simulasi kebakaran, cara menggunakan APAR dan hydrant, evakuasi kebakaran, cara P3K. Terdapat latihan khusus untuk anggota tanggap darurat berupa latihan fisik untuk menangani keadaan darurat. In house training tersebut dilakukan oleh petugas keamanan (SATPAM). Training ini wajib diikuti semua tenaga kerja perusahaan dari pegawai tetap hingga outsourcing.

\section{Sarana Proteksi Kebakaran Aktif (Alarm Kebakaran dan Detektor Asap)}

Sistem deteksi kebakaran awal yang digunakan adalah jenis detector asap (smoke detector). Jenis alarm yang digunakan adalah alarm bell. Jumlah smoke detector ada 4 yaitu dua (2) di panel depan dan dua (2) di pelleting. Prinsip kerjanya adalah alarm akan berbunyi secara otomatis apabila detector asap menerima rangsangan asap. Setelah alarm berbunyi dan lokasi kebakaran diketahui melalui control panel yang terpasang di pos keamanan, maka petugas pemadam melakukan tindakan pemadaman lebih lanjut.

\section{Sarana Proteksi Kebakaran Aktif (Alat Pemadam Api Ringan/APAR)}

Pada area perusahaan terdapat 84 unit APAR yang dimana terdiri dari 4 jenis APAR yaitu Dry Chemical Powder, Karbondioksida $\left(\mathrm{CO}_{2}\right)$, foam dan gas. Perusahaan lebih bayak menggunakan APAR jenis tepung kering (dry chemical powder) karena banyak bahan listrik.

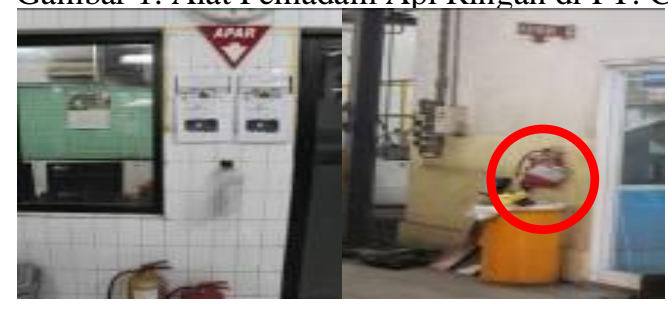

Corresponding Author: Rr. Vigna Maya Kosha,

Evaluasi Sistem Pencegahan Kebakaran di PT. Charoen Pokphand Indonesia Plant Krian, Sidoarjo, Jawa Timur 
Sumber: data sekunder

\section{Sarana Proteksi Kebakaran Aktif (Hydrant)}

Hydrant yang terdapat di perusahaan adalah sejumlah 35 unit hydrant. System kerja dari hydrant ini bekerja secara estafet dari ketiga sitem pengoperasian tiga alat yang berbeda-beda fungsi dan cara kerjanya yaitu antara Jockey pump, Diesel pump, dan hydrant. Cara kerja yang berbeda ini sesuai dengan tekanan yang dibutuhkan pada saat memadamkan api atau pada saat panel-panel pada pengoperasian hydrant ini bekerja. Untuk hydrant outdoor menggunakan sumber air dari saluran air dari sumur artesis atau kolam di belakag pabrik yang disalurkan melalui pipapipa yang berwarana merah, pada hydrant indoor biasanya menggunakan hose reel dengan sumber air yang berasal dari tanki-tanki yang berada di lantai bagian atas. Tekanan hydrant yaitu 8 bar.

\section{Sarana Proteksi Kebakaran Aktif (Hose reel)}

Hose reel ini terdapat dibagian feed mill (bagian produksi). Pada setiap lantai unit produksi atau feed mill terdapat satu hose reel. Hose reel yang terdapat di perusahaan berjumlah 9 unit hose reel. Tekanan dari hose reel adalah 4 bar. Panjang selang hose reel adalah 25 meter dengan diameter 1 inchi.

\section{Sistem Proteksi Kebakaran Pasif (Tangga Darurat)}

Tangga darurat yang terdapat di PT. Charoen Pokphand Indonesia, Krian sejak tahun 1996 terletak pada setiap lantai gedung produksi tepatnya dibagian luar bangunan. Permukaan anak tangga dan bordes tangga padat, tahan gelincir dan bebas dari tonjolan yang dapat menebabkan pengguna tangga jatuh. Kemiringan anak tangga tidak lebih dari $2 \mathrm{~cm}$ per $\mathrm{m}(1 / 4$ inci per $\mathrm{ft})$ (kemiringan $1: 48)$. Tidak ada variasi lebih dari $1 \mathrm{~cm} \mathrm{(3/16}$ Gambar 2. Penerangan Darurat di PT. CPI Krian

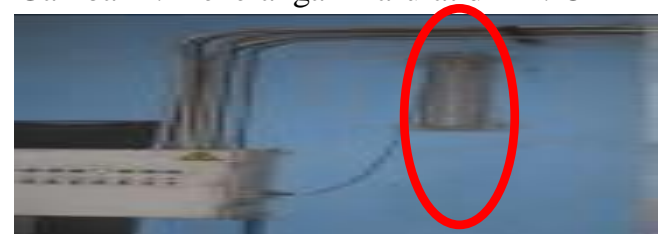

Sumber: data sekunder

\section{Sistem Proteksi Kebakaran Pasif (Jalur Evakuasi)}

Sistem pemberitahuan evakuasi, yang meliputi penanggung jawab evakuasi adalah pimpinan tim penanggung jawab di setiap departemen yang akan mengevakuasi seluruh tenaga kerja yang berada di departemennya untuk diarahkan di tempat aman sementara yang terdekat dengan area kerja masing-masing departemen. Kemudian seluruh tenaga kerja yang dievakuasi diarahkan untuk menuju ke assembly point yang telah ditentukan. Setelah seluruh tenaga kerja kumpul setiap penanggung jawab departemen mengecek seluruh tenaga inci) didalam kedalaman anak tangga yang bersebelaan atau di dalam ketinggian dari tinggi anak tangga yang bersebelahan.

\section{Sistem Proteksi Kebakaran Pasif (Pintu Darurat)}

Pintu darurat yang terdapat di PT. Charoen Pokphand Indonesia, Krian sejak tahun 1996 terletak pada setiap lantai gedung produksi tepatnya dibagian luar bangunan. Bukaan pintu untuk sarana jalan ke luar memiliki lebar bersih $80 \mathrm{~cm}$ (32 inci). Ketinggian permukaan lantai pada kedua sisi pintu tidak boleh berbeda lebih dari $12 \mathrm{~mm}$ ( $1 / 2$ inci). Ketinggian ini dipertahankan pada kedua sisi jalur pintu pada jarak sedikitnya sama dengan lebar daun pintu yang terbesar. Tinggi ambang pintu tidak menonjol lebih dari $12 \mathrm{~mm}$ ( $1 / 2$ inci). Pada jalur pintu dimiringkan dengan kemiringan tidak lebih curam dari 1 : 2. Setiap pintu pada sarana jalan keluar dari jenis engsel sisi atau pintu ayun. Pintu belum dirancang dan dipasang sehingga mampu berayun dari posisi manapun hingga mencapai posisi terbuka penuh.

\section{Sistem Proteksi Kebakaran Pasif (Penerangan Darurat)} Penerangan darurat yang tersedia di PT. Charoen Pokphand Indonesia, Krian yaitu terletak di setiap ruangan di kantor produksi dan pada ruangan proses produksi. Sistem penerangan darurat ditata untuk menyediakan iluminasi yang diperlukan secara otomatis di dalam kejadian terputusnya pencahayaan normal, seperti pada setiap kegagalan dari prasarana umum atau suplai tenaga listrik luar lainnya, setiap gerakan manual, termasuk pembukaan tak sengaja sebuah sakelar yang mengendalikan fasilitas penerangan normal. kerja apakah sudah lengkap atau masih ada yang tertinggal di dalam gedung.

\footnotetext{
Sistem Proteksi Kebakaran Pasif (Titik Kumpul Evakuasi)

Titik kumpul evakuasi yang tersedia di PT. Charoen Pokphand Indonesia, Krian yaitu terletak didepan kantor pemasaran bagian depan dan di depan pos satpam. Secara ideal, daerah yang harus terlindungi dari bangunan yang terkena dampak dari bangunan yang terbakar dan dimungkinkan untuk dapat dipindahkan ke tempat yang lebih jauh dari kemungkinan sumber bahaya.
} 
JPH RECODE Vol. 1 No. 1 (2017)

Gambar 3. Titik Kumpul Evakuasi di PT CP. Krian

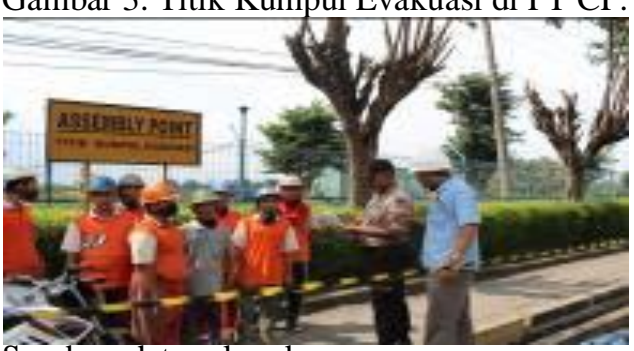

Sumber: data sekunder

\section{Inspeksi Kebakaran}

Terdapat Inspeksi kebakaran di PT. Charoen Pokphand Indonesia, Krian dan dilakukan setiap sebulan sekali oleh Tim SHE (Safety, Health, Environment). Plant manager sebagai penanggung jawab saat inspeksi.

Inspeksi yang terdapat pada PT. Charoen Pokphand Indonesia Krian meliputi inspeksi K3, inspeksi P2K3 dan isnpeksi peralatan pemadam. Inspeksi mengenai kebakaran meliputi, inspeksi alat pemadam api ringan (APAR), dan inspeksi hydrant kebakaran. Perlengkapan dokumen inspeksi kebakaran digabung dengan daftar periksa inspeksi $\mathrm{K} 3$ yang diadakan setiap bulan sekali.

\section{Pengendalian Bahaya/ Pencegahan.}

Di PT. Charoen Pokphand Indonesia, Krian sudah terdapat pengendalian bahaya/ pencegahan yang sistematis dan sudah terlaksana, yaitu sudah terlaksananya pengendalian sumber api, yaitu melalui sistem ijin kerja, dimana semua pekerjaan yang meggunakan sumber api atau dapat menimbulkan api harus memperoleh ijin kerja panas (hot work permit). Pengendalian sumber bahan bakar juga sudah terlaksana di PT. Charoen Pokphand Indonesia, Krian yaitu dengan cara mengamankan tempat penyimpanan bahan bakar, gudang penimbunan bahan kimia, proses penggunaan, dan pengangkutannya.

Menetapkan zona larangan merokok di tempat kerja yang berbahaya dan menyimpan bahan mudah terbakar adalah salah satu bentuk upaya pengendalian/ pencegahan di PT. Charoen Pokphand Indonesia, Krian. Selain itu, faktor lain yang perlu mendapat perhatian adalah instalasi listrik khususnya kelaikan, kondisi dan cara penggunaannya. Upaya yang dilakukan PT. Charoen Pokphand Indonesia, Krian yaitu membuat area merokok yang berjumlah 4 area terletak disekitar pinggir pabrik antara lain 1 area terletak didepan bagian packing, 1 area terletak didepan store room, dan 1 area terakhir yang terletak di depan gudang.

\section{PEMBAHASAN}

\section{Kebijakan Manajemen Tentang Pencegahan} Kebakaran

Kebakaran dapat terjadi kapan saja dan dimana saja serta menimbulkan banyak permasalahan bagi perusahaan dan pekerja serta mengakibatkan berbagai macam kerugian, dan hasil wawancara yang telah dilakukan bahwasanya pernah terjadi kebakaran di PT. Charoen Pokphand Indonesia Krian sehingga perlu adanya suatu kebijakan mengenai upaya pencegahan dan penanggulangan terhadap kebakaran.

Terdapat SOP (Standart Operation Prosedure) tentang evakuasi keadaan darurat, APAR dan Hydrant, pemadam kebakaran, keselamatan kerja kelistrikan, penyelidikan insiden dan pelaporannya, keselamatan kerja di kantor, memasuki dan bekerja di ruang sempit terkurung, keselamatan kerja dan safety audit. Pembuatan SOP dibuat berdasarkan Undang-undang No. 1 Tahun 1970 tentang keselamatan dan kesehatan kerja.

Perusahaan telah mempunyai kebijakan K3 dan menjamin komitmen terhadap penerapan Sistem Manajemen Keselamatan dan Kesehatan Kerja di perusahaan, hal ini sudah sesuai dengan peraturan menteri tenaga kerja nomor : PER/ 05/MEN/1996 tentang sistem manajemen keselamatan dan kesehatan kerja yang menyatakan bahwa perusahaan wajib menetapkan kebijaksanaan keselamatan dan kesehatan kerja dan menjamin komitmen terhadap penerapan SMK3.

Adanya SOP yang telah dimiliki oleh perusahaan dikategorikan baik, namun diperlukan adanya kebijakan khusus yang dibuat dan ditandatangani oleh pengusaha/ pengurus mengenai program pencegahan kebakaran yang memuat program pengendalian dan penanggulangan kebakaran mengingat pernah terjadi kejadian kebakaran.

Kebijakan K3 dan kebijakan lainnya seperti SOP yang ada di perusahaan ditinjau ulang secara berkala untuk menjamin bahwa kebijakan tersebut mencerminkan dengan perubahan yang terjadi dalam peraturan perundangan sesuai dengan maksud Keputusan Menteri Tenaga Kerja R.I. Hal ini diperlukan agar tidak terulangnya kejadian kebakaran dan terbentuknya komitmen manajemen bahwasana pengusaha menjamin agar kejadian kebakaran tersebut tidak akan terulang kembali.

\section{Organisasi Kebakaran}

Di PT. Charoen Pokphand Indonesia Krian sudah terdapat struktur organisasi khusus kebakaran. Namun di perusahaan semua karyawan juga mempunyai tugas dan tanggung jawab yang sama apabila terjadi kebakaran di area perusahaan dan semuanya terlibat dan menjadi anggota/ bagian dari unit oragnisasi kebakaran di perusahaan. Sudah dibentuk tim respon tanggap darurat 
JPH RECODE Vol. 1 No. 1 (2017)

atau Emmergency Response Team (ERT) yang terdapat identifikasi bahaya dan pengendalian risiko yang dilakukan pada struktur organisasi Panitia Pembina Keselamatan dan terdapat rincian risiko pekerjaan yang dapat menimbulkan Kesehatan Kerja (P2K3) pada divisi emergency safety, kebakaran.

terdapat lima orang anggota dan seorang ketua koordinator yaitu seorang ahli K3 yang bekerja di PT. Charoen Pokphand Indonesia Krian. Hal ini sudah sesuai dengan teori dari Ramli, 2010 yaitu untuk megelola upaya pencegahan kebakaran diperlukan pengorganisasian yang baik misalnya dengan membentuk organisasi kebakaran, baik bersifat struktural maupun non struktural.

\section{Prosedur Kebakaran}

Menurut Ramli (2010) untuk mengelola upaya pencegahan kebakaran diperlukan suatu prosedur atau tata cara melakukan penanggulangannya. Hasil penelitian menunjkkan bahwa di PT. Charoen Pokphand Indonesia Krian sudah terdapat prosedur tertulis mengenai pencegahan dan penanggulangan kebakaran yang memuat peran, tugas dan tanggung jawab dari setiap karyawan jika terjadi kebakaran di perusahaan.

Perusahaan memiliki prosedur untuk menghadapi keadaan darurat atau bencana diantaranya adalah kebakaran dalam suatu Standard Operating Procedure (SOP). Di dalam SOP tersebut terdapat bagan alir alur penanggulangan kebakaran. Hal tersebut sudah sesuai dengan Keputusan Menteri Tenaga Kerja R.I no : KEP186/MEN/1999 tentang unit penanggulangan kebakaran di tempat kerja Bab 1 Pasal 2 ayat 4d yang menyatakan bahwa rencana penanggulangan keadaan darurat kebakaran harus terdapat prosedur dalam menghadapi keadan darurat bahaya kebakaran dan sesuai dengan Keputusan Menteri Tenaga Kerja R.I No. : Kep-186/MEN/1996 yang menyatakan bahwa untuk menanggulangi kebakaran di tempat kerja, diperlukan adanya peralatan proteksi kebakaran yang memadai, petugas penanggulangan kebakaran yang di tunjuk khusus untuk itu, serta dilaksanakannya prosedur penanggulangan keadaan darurat.

\section{Identifikasi Bahaya Kebakaran}

Bahaya kebakaran dapat bersumber dari proses produksi, material atau bahan yang digunakan, kegiatan kerja yang dijalankan dalam perusahaan serta instalasi yang mengandung potensi risiko kebakaran. Di PT. Charoen Pokphand Indonesia, Krian sudah melakukan identifikasi bahaya, penilaian dan pengendalian risiko di tempat kerja terutama di tempat yang pernah terbakar yaitu di PT. CPI Krian yang mencakup sumber potensi bahaya dan juga pengendalian risikonya.

Mengingat pernah terjadi kebakaran pada tahun 2013 lalu maka risiko kebakaran di PT. Charoen Pokphand Indonesia, Krian termasuk risiko kebakaran tinggi karena pernah terjadi kebakaran dengan tingkat keparahan berat maka identifikasi bahaya dan penilaian risiko perlu dilakukan secara rinci mengenai kegiatan apa saja yang dapat menimbulkan kebakaran beserta pengendalian apa yang dibutuhkan jika terjadi kebakaran. Cara identifikasi dan penilaian risiko yang telah dilakukan PT. Charoen Pokphand Indonesia, Krian sudah tepat karena dari hasil

\section{Pembinaan dan Pelatihan}

Menurut hasil wawancara dengan SHE Coordinator telah dilakukan oleh di PT. Charoen Pokphand Indonesia Krian dengan diadakannya in house training yang diadakan setiap satu tahun dua kali yang diikuti oleh semua pekerja tetap saja (tanpa pekerja outsourching). Hal tersebut telah sesuai dengan Undang-undang nomor 1 Tahun 1970 tentang keselamatan kerja yang menyatakan bahwa pengurus diwajibkan menyelenggarakan pembinaan bagi semua tenaga kerja yang berada dibawah pimpinannya, pencegahan kecelakaan dan pemberantasan kebakaran serta peningkatan keselamatan dan kesehatan kerja, juga pemberian pertolongan pertama pada kecelakaan (P3K).

\section{Sarana Proteksi Kebakaran.}

Berikut penjelasan mengenai sarana proteksi kebakaran aktif yang terdapat di PT. Charoen Pokphand Indonesia Krian meliputi : Sistem Alarm dan Detektor Asap, pada sarana sistem alarm dan detektor PT. Charoen Pokphand Indonesia, Krian sudah memasang sistem alarm dan detektor. Sistem alarm dipasang pada setiap lantai di kantor dan area produksi. Sistem detektor yang dipakai di PT. Charoen Pokphand Indonesia, Krian adalah detektor asap (smoke detector) yaitu detektor yang akan aktif jika menerima asap. Di PT. Charoen Pokphand Indonesia, Krian pada setiap luas lantai $92 \mathrm{~m}^{2}$ dipasang satu detektor asap atau satu alat penangkap asap yang sesuai dengan Peraturan Menteri Tenaga Kerja Republik Indonesia No.2 Tahun 1983 yaitu tentang Instalasi Alarm Kebakaran Automatik.

Pemeliharaan dan pengujian sistem alarm dan detektor asap di PT. Charoen Pokphand Indonesia, Krian yaitu pemeriksaan secara bulanan. Pemeliharaan dan pengujian ini meliputi mengadakan simulasi kebakaran, memeriksa lampu-lampu indikator, memeriksa fasilitas penyediaan sumber tenaga darurat, memeriksa kondisi dan kebersihan panel indikator dan mencatat hasil pemeliharaan dan pengujian yang sesuai dengan PERMENAKER RI No. 2 Tahun 1983, namun pemeliharaan dan pengujian ini tidak dilakukan oleh konsultan kebakaran tetapi dilakukan oleh tim K3 yang berada di perusahaan.

Alat Pemadam Api Ringan (APAR), pemasangan APAR di PT. Charoen Pokphand Indonesia, Krian yaitu setiap APAR ditempatkan pada posisi yang mudah dilihat dengan jelas, setiap APAR dipasang menggantung pada dinding dengan penguat sekang atau ditempatkan dalam lemari atau peti (box) yang dikunci dan diberi kaca aman (safety glass), dan semua tabung APAR berwarna merah yang sesuai dengan PERMENAKERTRANS No. 4 Tahun 1980 tentang syarat-syarat pemasangan dan pemeliharaan APAR. Namun, adapun yang belum sesuai dengan peraturan tersebut, yaitu masih terdapat APAR yang berada di dalam lemari atau peti (box) yang tidak diberi kaca melainkan ditutup dengan kardus serta didalam lemari APAR tersebut terdapat benda-benda yang tidak seharusnya

Corresponding Author: Rr. Vigna Maya Kosha,

Evaluasi Sistem Pencegahan Kebakaran di PT. Charoen Pokphand Indonesia Plant Krian, Sidoarjo, Jawa Timur 
JPH RECODE Vol. 1 No. 1 (2017)

berada di dalam lemari seperti telepon genggam (handphone), gelas kosong dan tutup botol.

Pemeliharaan APAR di PT. Charoen Pokphand Indonesia, Krian yaitu dilakukan pemeriksaan dalam jangka waktu setiap 6 bulan sekali dilakukan oleh Departemen SHE. Pengecekan dan perawatan APAR meliputi kondisi pin yang terpasang, kondisi tabung, selang, jenis/tipe dan masa kadaluarsa. Apabila ditemukan kecacatan, maka APAR langsung diganti dengan yang baru atau apabila rusak dan tidak bisa dipakai lagi, APAR langsung diservice ke pihak lain di luar perusahaan. Pemasangan APAR sudah merata di bagian produksi dan pemeliharaan APAR sudah sesuai dengan PERMENAKERTRANS No. 4 Tahun 1980 tentang syarat-syarat pemasangan dan pemeliharaan APAR. Hydrant, terdapat 35 unit hydrant yang tersebar di PT. Charoen Pokphand Indonesia Krian.

Perlengkapan hydrant yang ada di PT. CPI Krian adalah pompa hydrant yang terletak di bagian belakang pabrik yang di pasang berdekatan dengan kolam air, pilar hydrant dan selang pemadam api (hose reel). Sistem kerja dari hydrant ini bekerja secara estafet dari ketiga sistem pengoperasian, tiga alat yang berbeda-beda fungsi dan cara kerjanya yaitu antara joockey pump, diesel pump, dan hydrant. Hal ini sudah sesuai dengan peraturan daerah khusus ibu kota Jakarta Nomor 8 Tahun 2008 tentang pencegahan dan penanggulangan bahaya kebakaran Pasal 19 yaitu bahwa sistem pipa tegak dan slang kebakaran serta hydrant halaman terdiri dari pipa tegak, slang kebakaran, hydrant halaman, penyediaan air dan pompa kebakaran.

Selang dan pancaran air yang ada dapat menjangkau seluruh ruangan yang dilindungi dan dipasang minimal 1 titik hydrant di setiap $800 \mathrm{~m}^{2}$, dan setiap kotak hydrant dicat merah dan bertuliskan warna putih sehingga sesuai dengan Keputusan Menteri Pekerjaan Umum No. 02/KPTS/1985 tentang Penentuan Pencegahan dan Penanggulangan Kebakaran pada gedung bertingkat. Namun adapun Terdapat beberapa kotak hydrantoutdoor yang kurang baik seperti kacanya pecah, retak dll, serta peletakannya yang terhalang oleh material bahan sehingga belum sesuai dengan peraturan Keputusan Menteri Pekerjaan Umum No. 02/KPTS/1985 bahwa penempatan kotak hydrant gedung harus mudah dibuka, dilihat dan dijangkau serta tidak terhalang benda lain.

Pengecekan dan perawatan hydrant dilakukan oleh Departement SHE setiap satu bulan sekali. Pengecekan itu meliputi pemeriksaan tekanan, valve, kondisi cat, safety sign, nozzle, tes mesin serta kondisi selang. Hose reel, penggulung slang yang dimiliki oleh PT. Charoen Pokphand Indonesia memiliki pengesahan, terdapat dokumen teknis seperti gambar pemasangan dan petunjuk pemeliharaan. Sistem persediaan air dapat menjamin kebutuhan air untuk operasi pemadaman. Hal ini sesuai dengan Instruksi Menteri Tenaga Kerja No. 11 Tahun 1997.

Pengecekan dan perawatan hose reel dilakukan oleh Departement SHE setiap satu bulan sekali. Pengecekan itu meliputi pemeriksaan tekanan, kondisi cat, safety sign, nozzle, serta kondisi slang. Berikut adalah penjelasan mengenai sarana proteksi kebakaran pasif yang terdapat di
PT. Charoen Pokphand Indonesia Krian meliputi : tangga darurat, permukaan anak tangga padat, tahan gelncir, dan bebas dari tonjolan atau bibir yang dapat menyebabkan pengguna tangga jatuh dam kemiringan anak tangga tidak lebih dari $2 \mathrm{~cm}$ sudah sesuai dengan Standar Nasional Indonesia 03 - 1746 - 2000. Sarana jalan keluar yang lebih dari $75 \mathrm{~cm}$ (30 inci) diatas lantai dilengkapi dengan pagar pengaman untuk mencegah jatuh dari sisi yang terbuka, pagar pegangan dan rel pegangan tangan terus menerus sepanjang tangga hingga pada belokan tangga sudah sesuai dengan Standar Nasional Indonesia $03-1746-2000$.

Tangga darurat yang ada di PT. Charoen Pokphand Indonesia, Krian secara keseluruhan sudah memenuhi Standar Nasional Indoneisa 03 - 1746 - 2000, Pintu darurat memiliki lebar bersih $80 \mathrm{~cm}$ (32 inci), pintu yang memiliki pasangan daun pintu memiliki lebar bersih $80 \mathrm{~cm}$ (32 inci) dan ketika pintu darurat terbuka penuh tidak ada yang menghalangi. Pintu darurat di PT. Charoen Pokphand Indonesia, Krian sudah sesuai dengan Standar Nasional Indonesia 03 - 1746 - 2000. Pintu darurat di PT. Charoen Pokphand Indonesia, Krian dirancang dan dipasang jika pintu pada sisi jalan keluar dibuat, mampu untuk mengayunkan pintu dari posisi manapun sampai penggunaan sepenuhnya, pada sisi jalan keluar dari masingmasing pintu, terdapat tanda yang mudah dilihat dengan tulisan "Dalam keadaan darurat, dorong untuk buka". Hal ini sesuai dengan Standar Nasional Indonesia 03 - 1746 2000.

Penerangan Darurat di PT. Charoen Pokphand belum terdapat penerangan darurat yang sebagaimana dalam Standar Nasional Indonesia 03 - 1746 - 2000 tentang tata cara perencanaan dan pemasangan sarana jalan ke luar untuk penyelamatan terhadap bahaya kebakaran pada bangunan gedung ; Jalur Evakuasi/ Penyelamatan Diri, tujuan diadakannya jalur evakuasi untuk mencegah terjadinya kecelakaan atau luka pada waktu melakukan evaluasi pada saat kebakaran terjadi yang meliputi pintu darurat, tangga darurat, tempat aman sementara dan tempat aman mutlak (Assembly Point) (PT. Petrokimia Gresik, 1998). PT. Charoen Pokphand Indonesia, Krian juga memiliki jalur penyelamatan diri sesuai dengan teori tersebut. Untuk menjamin berhasilnya strategi evakuasi diperlukan sistem pemberitahuan evakuasi. PT. Charoen Pokphand Indonesia, Krian telah membuat strategi evakuasi, titik Kumpul Evakuasi (Assembly Point) yaitu tempat berkumpul untuk orang yang dievakuasi jauh dari gedung untuk menjamin setiap orang aman dari bencana, tempat berkumpul juga harus terlindungi dari bangunan yang terkena dampak dari harus dimungkinkan dapat dipindah ke tempat yang jauh dari risiko sumber bahaya. Hal ini sesuai dengan Peraturan Menteri Hukum dan Hak Asasi Manusia Republik Indonesia Nomor 28 Tahun 2013 tentang manajemen penanggulangan kebakaran di lingkungan.

\section{Inspeksi Kebakaran}

Inspeksi yang telah dilakukan berupa inspeksi K3, inspeksi $\mathrm{P} 2 \mathrm{~K} 3$ dan inspeksi peralatan pemadam. Kegiatan 
JPH RECODE Vol. 1 No. 1 (2017)

inspeksi K3 yaitu berupa pemeriksaan APD, prosedur namun belum terdapat penerangan darurat, sudah terdapat keadaan darurat dan SOP, fasilitas kotak P3K, keselamatan bahan kimia berbahaya, penyimpanan dan penanganan material. Kegiatan inspeksi pemadam kebakaran meliputi inspeksi APAR dan Hydrant. Pemeriksaan peralatan berguna untuk agar saat terjadi kebakaran, peralatan pemadam kebakaran yang tersedia berfungsi. Oleh karena itu, APAR harus diperiksa dan diinspeksi secara berkala yaitu setiap 6 bulan yang dilaksanakan oleh tim K3 langsung atau petugas tanggap darurat. Inspeksi peadam kebakaran di PT. Charoen Pokphand Indonesia, Krian dilakukan oleh tim K3. Inspeksi ini berkategori baik karena sudah terdapat inspeksi kebakaran yang berpa inspeksi sarana fisik kebakaran berupa alat pemadam api dan kondisi tempat kerja seperti : petunjuk jalan penyelamat, lampu penerangan darurat, tangga darurat, titik kumpul evakuasi menurut Ramli (2010).

\section{Pengendalian Bahaya atau Pencegahan}

Upaya pengendalian bahaya atau pencegahan timbulnya kebakaran yang telah dilakukan oleh PT. Charoen Pokphand Indonesia, Krian adalah berupa pengendalian sumber api melalui membuat area merokok yang berjumlah 4 area terletak disekitar di area produksi, serta memasang stiker dilarang merokok yang terpasang di setiap area kerja agar memudahkan tenaga kerja melihat peringatan tersebut sehingga meminimalisasikan sumber penyalaan api secara tidak sengaja termasuk didalamnya, pengendalian sumber bahan bakar seperti pengaman tempat penyimpanan bahan bakar, rambu-rambu keselamatan dan bahaya kebakaran. Menurut Ramli (2010), upaya terpenting adalah mencegah kebakaran atau menghindari terjadinya kebakaran melalui program pencegahan kebakaran yang dilakukan secara terencana. Di PT. Charoen Pokphand Indonesia, Krian sudah terdapat program tertulis mengenai pengendalian bahaya yang dibuat khusus untuk penanggulangan dan mencegah kebakaran. Pembuatan SOP (Standart Operating Procedure) memuat langkah-langkah tanggap darurat. Pengendalian bahaya atau pencegahan berkategori baik karena sudah terdapat upaya yang dilakukan oleh perusahan secara tidak tertulis maupun tertulis yang terdapat pada SOP yang bertujuan untuk mencegah terjadinya adanya kebakaran termasuk peringatan berupa poster dan rambu-rambu tentang kebakaran.

\section{KESIMPULAN}

Pada program pencegahan kebakaran sudah terdapat kebijakan tentang pencegahan dan penanggulangan kebakaran dan sudah berjalan, sudah terbentuk organisasi kebakaran dan sudah bekerja sesuai tugas masing-masing, terdapat prosedur kebakaran, terdapat identifikasi bahaya kebakaran, adanya pembinaan dan pelatihan yang dilakukan secara rutin, sistem proteksi kebakaran aktif yang secara keseluruhan sesuai dengan peraturan yang berlaku namun masih terdapat beberapa APAR yang belum sesuai dengan peraturan perundangan, sistem proteksi kebakaran pasif secara keseluruhan sesuai dengan peraturan yang berlaku

inspeksi kebakaran dan terdapat pengendalian bahaya/ pencegahan. Gambaran sistem pencegahan kebakaran bernilai baik karena telah memuat semua elemen yang harus dijalankan dalam mengelola bahaya kebakaran.

\section{DAFTAR PUSTAKA}

Departemen Pekerjaan Umum, 1985. Keputusan Menteri Pekerjaan Umum No. 02/KTPS/1985. Tentang Ketentuan Pencegahan dan Penanggulangan Kebakaran Pada Bangunan Gedung. Jakarta.

Departemen Pekerjaan Umum, 1999. Keputusan Menteri Pekerjaan Umum No. 11/KTPS/2000. Tentang Ketentuan Teknis Manajemen Penanggulangan Kebakaran di Perkotaan. Jakarta.

Departemen Tenaga Kerja. 1980. Peraturan Menteri Tenaga Kerja No. Per-01/MEN/1980. Tentang Syarat-Syarat Pemasangan \& Pemeliharaan Alat Pemadam Api Ringan, Jakarta.

Departemen Tenaga Kerja. 1983. Peraturan Menteri Tenaga Kerja No. Per-02/MEN/1983. Tentang Instalasi Alarm Kebakaran Otomatik, Jakarta.

Departemen Tenaga Kerja. 1999. Keputusan Menteri Tenaga Kerja No. Kep-186/MEN/1999. Tentang Unit Penanggulangan Kebakaran di Tempat Kerja, Jakarta.

Ramli, S. 2010. Petunjuk Praktis Manajemen Kebakaran. Jakarta: Dian Rakyat.

Ramli, S. 2010. Sistem Manajemen Keselamatan \& Kesehatan Kerja. Jakarta: Dian Rkyat.

Ramli, S. 2010. Pedoman Praktis Manajemen Bencana. Jakarta: Dian Rakyat.

Ramli, S. 2010. Pedoman Praktis Manajemen Risiko dalam Prespektif K3 OHS Risk Management. Jakarta: Dian Rakyat.

Sugiyono, 2011. Statistika Untuk Penelitian. Bandung: Alfabeta. 